
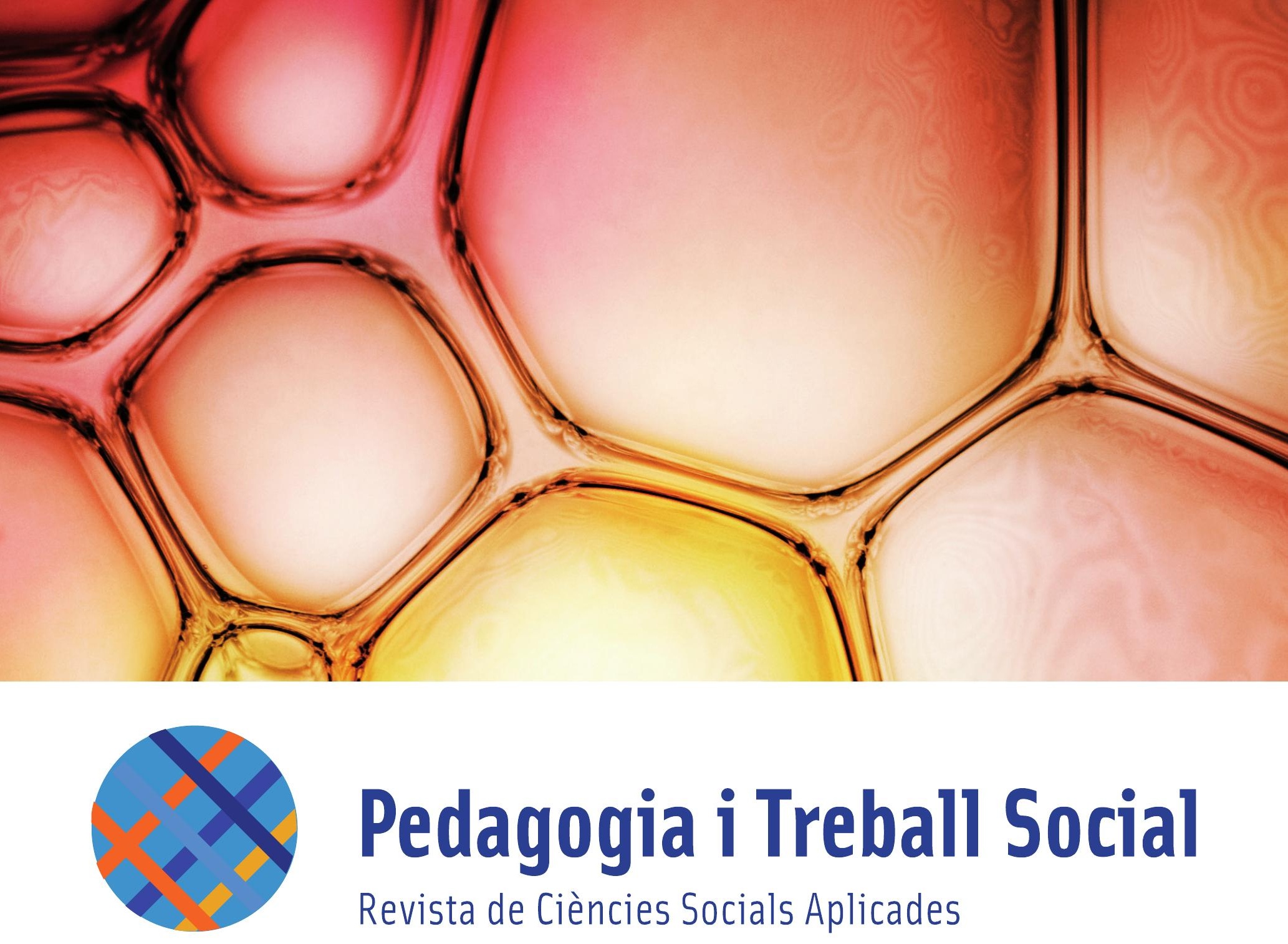

\title{
Pedagogia i Treball Social
}

Revista de Ciències Socials Aplicades

Dipòsit Legal: GI.904-2010

ISSN: $2013-9063$

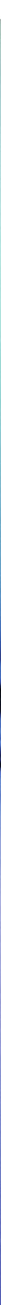




\section{Article Artículo Paper L'ampliació del temps \\ 3 d'aprenentatge, una pràctica inclusiva que millora el rendiment acadèmic de tot l'alumnat}

\section{Rosa Valls i Carol ${ }^{1}$}

Departament de Teoria i Història de l'Educació de la Universitat de Barcelona rosavalls@ub.edu

\section{Gregor Siles Molina ${ }^{2}$}

Departament de Teoria

i Història de l'Educació

de la Universitat de Barcelona gsilesm@ub.edu

\section{Resum}

La recerca $\mathrm{R}+\mathrm{D}$ «Formas de agrupación del alumnado y su relación con el éxito escolar: 'mixture', 'streaming' e inclusión (2009-2011)» ha realitzat una anàlisi quantitativa $\mathrm{i}$ una de qualitativa sobre la presència d'aquestes modalitats d'agrupació en els centres d'educació primària i secundària de l'Estat espanyol. Els resultats quantitatius reflecteixen que l'ampliació del temps d'aprenentatge és la pràctica inclusiva més implementada en els centres educatius. Una pràctica que pot suposar una alternativa a la separació per nivells de l'alumnat, que es dóna dins de la modalitat de streaming, i que ajuda a millorar aquells alumnes que tenen un nivell més baix. L'estudi qualitatiu mostra diferents formes de com s'aplica aquesta pràctica i com els centres que les vinculen més directament als

1. Rosa Valls. Doctora en Pedagogia. Professora del Departament de Teoria i Història de l'Educació de la Universitat de Barcelona

2. Gregor Siles. Doctorand en Pedagogia. Beca FI- Generalitat de Catalunya. Professor del Departament de Teoria i Història de l'Educació de la Universitat de Barcelona 
continguts instrumentals, a la vegada que aprofiten per al seu desenvolupament els recursos disponibles, tant de l'administració com de la comunitat, aconsegueixen una incidència més gran en la millora acadèmica de l'alumnat.

Paraules clau: ampliació del temps d'aprenentatge, rendiment escolar, èxit escolar.

\section{Resumen}

La investigación $\mathrm{I}+\mathrm{D}$ «Formas de agrupación del alumnado y su relación con el éxito escolar: 'mixture', 'streaming' e inclusión (2009-2011)» ha realizado un análisis cuantitativo y cualitativo sobre la presencia de estas modalidades de agrupación en los centros de educación primaria y secundaria de España. Los resultados cuantitativos reflejan que la ampliación del tiempo de aprendizaje es la práctica inclusiva más implementada en los centros educativos, una práctica que puede suponer una alternativa a la separación por niveles del alumnado, que se da dentro de la modalidad de streaming, y que ayuda a mejorar a aquellos alumnos que tienen un nivel más bajo. El estudio cualitativo muestra diferentes formas de cómo se aplica esta práctica y como aquellos centros que las vinculan más directamente a los contenidos instrumentales, a la vez que aprovechan para su desarrollo los recursos disponibles, tanto de la administración como de la comunidad, consiguen una mayor incidencia en la mejora académica del alumnado.

Palabras clave: ampliación del tiempo de aprendizaje, rendimiento escolar, éxito escolar.

\section{Abstract}

The research and innovation project "Student grouping and its relationship with academic success: Mixture, streaming and inclusion (2009-2011)" consisted of a quantitative and qualitative analysis of the presence of these groupings in elementary and secondary schools in Spain. Quantitative outcomes demonstrate that lengthening learning time is the most successful inclusive practice carried out in the schools. This is an alternative to tracking students into different classrooms as done in schools that use streaming and it 
helps to improve learning among students who struggle most. The qualitative study data shows the different ways these practices are implemented. At the same time, it highlights how schools that link them to major instrumental learning and efficiently allocate the resources available from the Government and from the community to improve students' academic learning.

Key words: Lengthening learning time, academic achievement, school success. 


\section{Introducció}

E1 projecte INCLUD-ED: Strategies for inclusion and social cohesion in Europe from education (2006 - 2011) $)^{3}$, la recerca europea de major nivell científic i dotació de recursos realitzada sobre el sistema escolar fins ara, ha definit les activitats d'ampliació del temps d'aprenentatge com una pràctica inclusiva, que ajuda a superar el fracàs escolar. En el marc d'aquest projecte, es van identificar tres modalitats d'agrupació, mixture, streaming i inclusion, que comporten un ús diferent dels recursos i una distribució diferent de l'alumnat, amb un potencial impacte de cadascuna en el rendiment acadèmic. A partir d'aquests resultats, la recerca MIXSTRIN, «Formas de agrupación del alumnado y su relación con el éxito escolar: 'mixture', 'streaming' e inclusión» (Plan Nacional I+D, Ministerio de Educación y Ciencia 2008-2011), ${ }^{4}$ ha analitzat com es desenvolupen les tres modalitats d'agrupació en els centres educatius de l'Estat espanyol. A partir d'una àmplia enquesta s'ha identificat quins models d'agrupació s'estan desenvolupant, i com, en els centres educatius de primària i secundària. En els resultats, l'única pràctica inclusiva que es va identificar de manera significativa, tant en els centres de primària com en els de secundària, és l'ampliació del temps d'aprenentatge. Així mateix, en els centres de secundària també es va identificar una altra pràctica, «l'optativitat inclusiva». En una segona fase de la recerca, es va realitzar un estudi qualitatiu en cinc centres educatius per analitzar els models d'agrupació i la seva relació amb els resultats acadèmics.

En aquest article expliquem els resultats del projecte MIXSTRIN, en relació amb la pràctica d'ampliació del temps d'aprenentatge. En un primer apartat, descrivim les diferents modalitats d'agrupació identificades en el projecte INCLUD-ED. En un segon punt, mostrarem la metodologia que s'ha seguit en la recerca MISXTRIN. Tot seguit detallarem els resultats del projecte MIXSTRIN referents a l'ampliació del temps d'aprenentatge; en el primer apartat, els resultats de l'enquesta, i en el segon, els de l'estudi qualitatiu. Finalitzarem l'article amb unes breus conclusions.

3. http://www.ub.edu/includ-ed/

4. http://mixstrin.wordpress.com/about/ 


\section{Formes d'agrupació de l'alumnat definides per la comunitat científica internacional}

El projecte INCLUD-ED (2011) va identificar tres modalitats d'agrupació d'alumnat, mixture, streaming i inclusion, i la seva relació amb el rendiment acadèmic, a partir de l'anàlisi dels sistemes educatius de la Unió Europea, així com de les teories que els sustenten, $\mathrm{i}$ dels resultats educatius obtinguts pels diferents països en estudis quantitatius de gran escala. ${ }^{5}$

El mixture ha estat definit com el model tradicional, una classe amb alumnat divers, tant en nivells de rendiment com de context sociocultural, i un únic professor. Una modalitat que, davant la diversitat que es dóna actualment en els centres educatius, té dificultats per aconseguir un alt rendiment acadèmic per a tot l'alumnat. Una alternativa al mixture és l'adaptació dels continguts i el currículum en funció del rendiment acadèmic de l'alumnat, pràctica que la Comissió Europea (2006) ha denominat streaming, i que els sistemes i centres educatius estan aplicant per afrontar la diversitat sociocultural i de nivells de rendiment de l'alumnat. Aquestes adaptacions, que poden anar dirigides a un alumne o grup d'alumnes, s'estan aplicant de diferents formes: separant l'alumnat per nivells de rendiment; separant de l'aula de referència un/a alumne/a o un grup d'alumnes per rebre reforç, i mitjançant adaptacions curriculars que rebaixen el nivell de continguts. Una altra pràctica de streaming és l'optativitat exclusiva, aquella elecció d'assignatures que limita a l'alumnat les possibilitats d'accedir a estudis universitaris.

La bibliografia científica ha evidenciat l'impacte negatiu que té l'streaming sobre l'alumnat que va a parar als grups de menor nivell. Posar un/una alumne/a en un grup de menor nivell, manifesta d'entrada les baixes expectatives que es tenen respecte a aquest alumnat, i és una decisió que es pren sovint des del centre educatiu unilateralment, sense consultar-ho a les famílies i als mateixos alumnes (Oliver i Gatt, 2010). En els grups de més baix nivell es donen habitualment uns continguts rebaixats i s'estimula menys el pensament crític (Chorzempa i Graham, 2006), a la vegada que es perden les interaccions amb l'alumnat més preparat (Zimmer, 2003; Puigdellívol i Krastina, 2010). Tots aquests aspectes

5. En concret: PISA (Programme for International Student Assessment, dut a terme per l'Organització per a la Cooperació i el Desenvolupament Econòmic), TIMSS (Trends in International Mathematics and Science Study) i PIRLS (Progress in International Reading Literacy Study, realitzats per la International Association for the Evaluation of Educational Assessment). 
influeixen en l'autoestima d'aquest alumnat i poden provocar un gran desencant respecte a la institució escolar per part d'aquest alumant i de les seves famílies (Braddock i Slavin, 1992; Oliver i Gatt, 2010). Així mateix, l'alumnat que pateix les adaptacions curriculars i va a parar als grups de menor nivell és sovint el més vulnerable de caure en l'exclusió social i educativa, perquè prové de contextos socioeconòmics baixos o de minories culturals, és d'origen immigrant, i/o procedeix d'educació especial (Youdell, 2003; De Haan i Elbers, 2005)..

La tercera modalitat identificada en el projecte INCLUD-ED és la inclusion, que recull les pràctiques que mantenen l'heterogeneïtat de l'alumnat, en nivells de rendiment i de context sociocultural, incorporant recursos per donar suport dins de l'aula, sense necessitat de separar per nivells, per tal que tot l'alumnat segueixi el currículum ordinari. Un d'aquests recursos és l'entrada de més professorat dins de l'aula, així com d'altres professionals i/o persones voluntàries que poden ser familiars de l'alumnat, veïns del barri, estudiants universitaris, etc. Altres pràctiques dins d'aquesta modalitat són: els desdoblaments en grups heterogenis, que permeten treballar les matèries instrumentals reduint la ràtio; les adaptacions curriculars individuals inclusives, en les quals no es redueix el contingut sinó que es modifiquen els mètodes per facilitar l'aprenentatge; l'optativitat inclusiva, o sigui, l'elecció d'assignatures que no limita l'accés a la realització d'estudis superiors; i l'ampliació del temps d'aprenentatge, és a dir, les activitats acadèmiques addicionals, en horari extraescolar. Aquesta darrera pràctica pot anar orientada a l'alumnat que té dificultats per seguir el nivell de classe, però també pot estar oberta a tot tipus d'alumnat, per ajudar a fer els deures o reforçar continguts, per a l'aprenentatge d'idiomes, etc. Els resultats del projecte MIXSTRIN ens han mostrat que aquestes activitats poden tenir diferents orientacions i organització.

\section{Metodologia}

L'estudi quantitatiu del projecte I+D MIXSTRIN, que ha permès identificar les modalitats d'agrupació de l'alumnat que s'estan desenvolupant en els centres educatius de primària i secundària de l'Estat espanyol, es va implementar mitjançant dos qüestionaris, un per a educació primària i un altre per a educació secundària, seguint els criteris definits en el projecte INCLUD-ED (2009), en relació amb les tres modalitats d'agrupació. Els dos qüestionaris anaven precedits per unes preguntes de caràcter sociodemogràfic (situació, professorat i perfil de l'alumnat) i sobre l'organització de les escoles (nombre de classes 
per cada curs). El qüestionari de primària estava format per un total de 39 preguntes, distribuïdes en cinc blocs temàtics: escoles que estableixen més d'un grup classe per curs, agrupacions i recursos humans dins de l'aula, alumnat fora de l'aula ordinària, adaptació curricular i extensió del temps d'aprenentatge. El qüestionari de secundària contenia 43 preguntes, organitzades en els mateixos blocs i amb un sisè bloc addicional sobre optativitat d'assignatures i relació amb els estudis futurs.

En el bloc referent a l'extensió del temps d'aprenentatge, i que analitzem aquí, es formulaven sis preguntes: si es realitzen activitats d'extensió de l'aprenentatge, quina orientació tenen, si implica l'absència a classes ordinàries, qui hi participa, qui les organitza, i qui decideix quin alumnat hi assisteix.

La població objecte de l'estudi han estat els centres educatius públics de primària i secundària de l'Estat espanyol. El volum de les dues submostres ha estat de 366 centres de primària i 316 centres de secundària, extrets de manera aleatòria simple. En la mostra de primària l'error acceptat se situa en el 5,1 \% (per a un 95 \% d'interval de confiança), i el de la mostra de secundària se situa en un error acceptat del 5,3 \% (amb el mateix marge de confiança). La implementació dels qüestionaris es va realitzar en el curs 2009-2010 i l'abast de l'estudi ha estat un total de 265.231 estudiants (37,5 \% de primària i 62,5 \% de secundària) i 26.689 docents (el $31 \%$ de primària davant del $69 \%$ de secundària).

Lestudi qualitatiu del projecte, dirigit a identificar les relacions entre les modalitats d'agrupació de l'alumnat i els resultats acadèmics, es va desenvolupar amb un enfocament metodològic comunicatiu crític (Gómez et al., 2006; Gómez, Puigvert i Flecha, 2011), perspectiva que parteix de diferents bases teòriques i interdisciplinàries, d'autors com $\mathrm{Ha}$ bermas, Freire, Mead, Shütz o Garfinkel. Aquesta metodologia es basa en les persones com a agents socials, amb una capacitat de llenguatge i acció que els permet contribuir a la creació de coneixement. Per a la seva consecució, es van realitzar cinc estudis de cas en centres educatius de l'Estat espanyol, dos en escoles d'educació primària i tres en instituts d'educació secundària; dos eren representatius de la modalitat de streaming (una escola i un institut) i tres, de la modalitat d'inclusion (una escola i dos instituts). Els criteris de selecció van ser: centres educatius que disposessin d'avaluacions externes del nivell de competències de l'alumnat i centres educatius similars -nivell socioeconòmic mitjà-baix i diversitat cultural de la població, com a factors que poden condicionar els resultats acadè- 
mics de l'alumnat i que aporten informació sobre l'alumnat més vulnerable, que necessita més actuacions educatives d'èxit per superar el risc de caure en l'exclusió social i educativa.

\section{L'ampliació del temps d'aprenentatge, resultats de l'enquesta estatal sobre formes d'agrupació de l'alumnat}

En els resultats de l'enquesta estatal del projecte MIXSTRIN, la mixture no apareix de forma significativa a les escoles de primària i ho fa en una tercera part dels centres de secundària. Les pràctiques de streaming són les més habituals: un $40 \%$ dels centres de primària i més del $60 \%$ dels centres de secundària adapten els objectius i continguts d'aprenentatge als diferents grups classe segons el nivell previ de coneixements. Un $80 \%$ de les escoles de primària i més del 40 \% dels centres de secundària organitzen activitats de reforç fora de l'aula ordinària dins de l'horari lectiu, principalment d'assignatures instrumentals.

Les pràctiques d'inclusion, que es donen de forma representativa tant en els centres de primària com de secundària, es fan en horari extraescolar, amb activitats d'ampliació del temps d'aprenentatge. Un $45 \%$ d'escoles de primària i un $44 \%$ dels centres de secundària ofereixen activitats d'aquest tipus, principalment orientades a millorar els nivells d'aprenentatge i dirigides a l'alumnat que té algun tipus de dificultat per diferents motius: socioeconòmics, per algun tipus de discapacitat, pel nivell educatiu més baix, perquè es tracta d'alumnat d'incorporació recent, immigrant o que pertany a minories ètniques. Són activitats dirigides a l'alumnat més vulnerable, aquell que, com assenyala la bibliografia científica, és el que sovint pateix les pràctiques de streaming. No obstant això, l'enquesta també mostra que molts centres obren aquestes activitats a tot l'alumnat.

L'organització d'aquestes activitats, assenyala l'enquesta, recau principalment en la direcció dels centres i en els equips d'orientació i en el professorat, i l'alumnat i les seves famílies hi tenen molt poca incidència. Així mateix, en la decisió sobre quin alumnat ha d'assistir a aquestes activitats, a primària hi tenen més pes les famílies de l'alumnat (un $12,3 \%$, que a secundària, on trobem un percentatge només d'un 6,01 \% de les famílies.

El resultats ens mostren que l'ampliació del temps d'aprenentatge és una activitat inclusiva que s'està desenvolupant en molts centres educatius de l'Estat espanyol, amb una 
clara orientació de reforç de l'aprenentatge per a aquells que més ho necessiten, per posar-los al nivell de la resta de l'alumnat. Però els mateixos resultats evidencien que no està destinada a superar la pràctica de l'streaming, per l'alt percentatge de centres que fan separació per nivells de rendiment o que realitzen activitats de reforç fora de l'aula ordinària, dins de l'horari lectiu.

\section{L'ampliació del temps d'aprenentatge i l'impacte en el rendiment acadèmic}

En els cinc centres analitzats en l'estudi qualitatiu del projecte MIXSTRIN, es desenvolupen activitats d'ampliació del temps d'aprenentatge, cosa que corrobora els resultats quantitatius, que reflectien que aquesta pràctica inclusiva és la d'implementació més gran, tant a primària com a secundària. Aquestes activitats es poden desenvolupar de diferents maneres, tant en l'orientació de l'aprenentatge com en la seva organització. En un dels centres estudiats (de secundària i modalitat streaming), aquestes activitats es limiten a l'alumnat que té alguna assignatura pendent de l'any anterior, i s'ofereixen de forma no obligatòria, tal com ens explicava una professora.

«Solamente en el caso de los alumnos que han suspendido el curso anterior hay unas clases de recuperación los miércoles por la tarde, que son voluntarias. Entonces va el alumnado que quiere, que sus padres le envían y... es el único caso que yo conozco. Las organiza el propio centro. Entonces hay profesorado que están con clases el miércoles por la tarde, que no van nada más que estos grupos de alumnos para recuperar la asignatura que tienen pendiente.»

En un altre dels centres (de primària i modalitat streaming), veiem que les activitats d'ampliació del temps d'aprenentatge són tallers de caràcter més lúdic que instrumental, amb una escassa oferta de reforç en l'horari extraescolar.

(A) «Hay inglés, pero bueno, prácticamente son más... más lúdicas que otra cosa.»

(B) «Para los más mayores, inglés, talleres de inglés, talleres de informática... talleres... este año hay un taller musical que también les está gustando. Para los más pequeños hay un taller de cocina, talleres de teatro también tienen, un taller de psi- 
comotricidad... y luego del APA pues hay talleres de inglés, más para... ya esos sí que los veo más de apoyo para niños a lo mejor que... que les cuesta más trabajo; hay un taller de pintura... el Ayuntamiento también organiza actividades deportivas.»

En els centres analitzats dins de la modalitat d'inclusion, s'observa com les activitats d'ampliació van directament dirigides a l'aprenentatge instrumental. Un exemple és la biblioteca tutoritzada (Aguilar et al., 2010), que trobem en els centres que formen part del projecte educatiu de les comunitats d'aprenentatge (Elboj et al., 2002) i que obre un espai en el temps extraescolar per oferir activitats d'aprenentatge instrumental, com per exemple reforç de continguts i/o tertúlies literàries dialògiques. Les persones que donen suport a aquestes activitats van des del professorat a monitors d'entitats o persones voluntàries de la comunitat, i a famílies de l'alumnat que també passen a rebre formació i a participar en tertúlies dialògiques (Aguilar et al., 2010). La participació de l'alumnat en tertúlies dialògiques, per a les quals han d'haver llegit prèviament un capítol o capítols d'un llibre -d'un clàssic universal-, i en les quals dialoguen igualitàriament entorn la lectura, és una activitat que alguns centres apliquen dins de l'horari lectiu i altres, com a ampliació del temps d'aprenentatge. És una pràctica d'èxit, avalada per la comunitat científica internacional, que millora la competència lectora i desenvolupa el pensament crític dels que hi participen (Flecha, 1997; Aubert et al., 2008; Flecha, Soler i Valls, 2008; INCLUD-ED, 2011). Un professor d'un institut de secundària de la modalitat d'inclusion ens explicava com l'alumnat millora en el nivell de lectura participant en les tertúlies dialògiques, que es realitzen a la biblioteca tutoritzada.

«Según lo que entiendo yo por biblioteca tutorizada, también queriendo hacer tertulias el nivel de mi alumnado era tan bajo tan bajo que al final me di cuenta de que, o sea si eran de tercero y cuarto, pues tuve que bajar a un nivel lector de seis años. Entonces claro, lo que pasa es que ya cuando alcanzamos el seis el nivel lector fue hacia arriba, pero me costó mucho tiempo, mucho tiempo. Y elegí, pues eso, un autor y los pocos recursos que había aquí en la biblioteca y con la tutora... coordinarme un poco (...) y sacarlos del barrio, llevármelos por ahí muchas veces a otras bibliotecas, siempre en el tema instrumental. (...) Siempre en el tema instrumental, potenciar la lectura.»

La gestió de les comunitats d'aprenentatge, mitjançant assemblees i comissions en les quals participen i prenen decisions el professorat, l'alumnat, els familiars, les entitats 
i altres membres de la comunitat, permet aprofitar els recursos disponibles en l'entorn de l'escola i destinar-los a l'aprenentatge. Un professor de secundària ens explicava com, en colllaboració amb una entitat, organitzen activitats d'ampliació d'aprenentatge: «Pero las otras actividades de las Hijas de la Caridad, que verdaderamente ahora están viniendo a las asambleas y hay bastante coordinación. Los niños vienen, meriendan y hacen una actividad lúdica, y les ayudan a hacer deberes.» Així mateix, en un altre centre de secundària i de la modalitat d'inclusion, vam veure com l'organització de les activitats d'ampliació del temps d'aprenentatge es duia a terme en el marc dels programes PROA (Programas de Refuerzo, Orientación y Apoyo), del Ministeri d'Educació i Ciència, en els quals s'ofereixen activitats de reforç en horari extraescolar o dins de l'horari escolar. En aquest centre es va decidir implementar-les només en horari extraescolar, per evitar fer streaming i separar del grup classe l'alumnat que ho necessités. Aquest programa permet al centre comptar amb dues monitores de reforç, a les quals s'afegeix una educadora de l'associació gitana que hi participa com a voluntària, i se sumen així esforços, amb recursos de l'administració i de la comunitat. D'altra banda, es garanteix la gratuïtat d'aquestes activitats, i això contribueix a superar les desigualtats, no només de nivell d'aprenentatge, sinó també les econòmiques, que sovint van associades i que poden limitar l'accés a aquests recursos. Una professora del centre ens va explicar com s'ofereix aquest reforç de l'aprenentatge i com cada vegada hi participa més alumnat.

«Entonces lo que hacemos es... pues hay dos monitoras que les ayudan en lo que necesiten, dudas, estudio, deberes, lo que necesiten. Hemos ido comprobando, pues, que cada día se quedan más, pues es un recurso que está ahí y que pues de hora y media, al final se suelen quedar dos horas... o pues eso, y que está funcionando muy bien. Entonces una de las monitoras que tenemos, incluso, es educadora de la Asociación Gitana, colaboradora aquí como voluntaria y bueno, trabaja con nosotros en las tutorías individualizadas y demás.»

Un altre dels centres estudiats, de secundària i de la modalitat d'inclusion, desenvolupa les activitats d'ampliació del temps d'aprenentatge dintre del pla d'acompanyament que ofereix la Junta d'Andalusia. Aquest pla consisteix en activitats de reforç extraescolar dirigides principalment a alumnes amb dificultats d'aprenentatge i/o que les famílies no els poden donar suport en l'estudi, que compensen les mancances en què sovint es trobem moltes llars d'un context socioeconòmic baix, de minories ètniques o d'immigrants. 
«Ese plan está dirigido al alumnado que tienen, por diversas causas, dificultad, si bien algo personal o por la familia, pues se le incluye en ese programa, y va por las tardes a revisión de sus tareas o supervisión de monitores, e incluye la ayuda, que a lo mejor no la encuentran en casa, y la pueden tener en el centro.»

L'experiència de l'alumnat mostra que, gràcies a l'assistència a aquestes activitats d'ampliació, estan millorant en el seu aprenentatge: «A mi un mes me falta alguna cosa de inglés y ahí voy y me ayuda mogollón. (...) Yo he aprobado dos asignaturas por PROA, y me han ayudado mucho a hacer redacciones.» Així mateix, tant el professorat com el mateix alumnat han pogut comprovar que el rendiment també baixa quan l'alumnat deixa d'assistir a aquestes sessions:

«Pero nosotros le aconsejamos, le sugerimos y hablamos con los padres e incluso con los chavales. Hace poco una chica empezó a no ir a PROA y en seguida lo notamos, que estaba bajando un poco el rendimiento, la motivación, si vas a clase sin hacer los deberes es como te abandonas más. Hablamos con la chica (...) y reconoció que no ir a PROA le estaba perjudicando, que no estaba participando igual en clase y ahora ha vuelto a empezar a ir y... mejor, mucho mejor. Se nota quien va a PROA, quien hace los deberes.»

Les activitats d'ampliació de l'aprenentatge obertes a tot l'alumnat, quant a nivells de rendiment i cursos, i en les quals es fomenta la cooperació en grups heterogenis, generen dinàmiques positives per potenciar l'aprenentatge també en aquests espais: «Van de todos, es bonito de entrar a veces, porque son chavales de todos los cursos que van con sus deberes, se ayudan entre ellos.» D'acord amb el professorat, aquestes activitats tenen efecte i ajuden a superar el desavantatge en el nivell d'aprenentatge de l'alumnat que hi acudeix: «Entendemos que sí, que al final eso repercute en la nota y suelen ser alumnos que luego, al final, se reenganchan.» No obstant això, també es detecten dificultats en els centres per aconseguir ampliar l'assistència a aquestes activitats de tot l'alumnat que necessita ajuda.

\section{Conclusions}

Els resultats de l'enquesta estatal sobre formes d'agrupació de l'alumnat del projecte MIXTRIN mostren que les pràctiques inclusives als centres educatius es donen de manera 
limitada i molt concreta, i que l'ampliació del temps d'aprenentatge és l'única que s'aplica de manera significativa als centres de primària i secundària, juntament amb l'optativitat inclusiva a secundària. Així mateix, les pràctiques de streaming, que separen l'alumnat per grups de nivell, realitzen adaptacions curriculars que disminueixen el nivell dels continguts i/o separen l'alumnat en grups de reforç fora de l'aula en l'horari lectiu, són les majoritàries en els centres educatius de l'Estat espanyol, malgrat que la bibliografia científica assenyala l'impacte negatiu que tenen sobre l'alumnat amb més dificultats.

Les activitats d'ampliació del temps d'aprenentatge, tant a primària com a secundària, posen un èmfasi especial en els grups d'alumnat amb més dificultats i que té més risc de patir exclusió social i educativa, com ara l'alumnat d'un context socioeconòmic baix, el que té algun tipus de discapacitat, el de nivell educatiu més baix, el d'origen immigrant o/i el que pertany a minories ètniques. El mateix alumnat que habitualment, en les pràctiques de streaming, va destinat als grups de menor nivell, surt fora de l'aula a rebre reforç instrumental, o se li rebaixen els continguts. Lorientació de les activitats és ajudar l'alumnat en el seu aprenentatge, i compensar les mancances que pugui tenir per seguir el currículum ordinari, però no sempre s'apliquen com a alternativa a les pràctiques de streaming.

Els resultats de l'estudi qualitatiu ens mostren diverses formes de com s'apliquen les activitats d'ampliació de l'aprenentatge, i hem trobat diferències importants entre els centres que apliquen pràctiques de streaming i els que apliquen pràctiques d'inclusion. En els primers, es tracta d'activitats molt concretes i limitades a l'alumnat que ho necessita, obertes a tot l'alumnat quan no són estrictament instrumentals, i en què de vegades predomina el caràcter lúdic. En els segons, estan orientades a activitats instrumentals, principalment dirigides a l'alumnat que ho necessita però obertes a tothom, fet que possibilita la cooperació entre l'alumnat de diferent nivell. En aquests centres també veiem com per a l'organització d'aquestes activitats s'aprofiten els recursos de la comunitat educativa i de l'administració.

Tots els centres, valoren positivament la realització d'aquestes activitats per a la millora del rendiment acadèmic de l'alumnat. No obstant això, el fet que aquesta actuació inclusiva es doni en horari extraescolar la converteix en no obligatòria i, per tant, fa que sigui més difícil assegurar que tot l'alumnat que necessita aquest suport addicional el rebi i, per tant, assegurar la igualtat de resultats per a tots. Una millor resposta a les necessitats de l'alumnat passaria per incorporar les actuacions inclusives a l'horari lectiu i a les activitats habituals a l'aula. 


\section{Bibliografia}

Aguilar, C., Alonso, M. J., Padrós, M. i Pulido, M. A. (2010). «Lectura dialógica y transformación en las Comunidades de Aprendizaje». Revista Interuniversitaria de Formación de Profesorado, (24) 1,31-44.

Aubert, A.; Flecha, A.; García, C.; Flecha, R. i Racionero, S. (2008). Aprendizaje dialógico en la sociedad de la información. Barcelona: Hipatia.

Braddock, J. H. i Slavin, R. E. (1992). Why Ability Grouping Must End: Achieving Excellence and Equity in American Education. Baltimore, MD: Center for Research on Effective Schooling for Disadvantaged Students.

Chorzempa, B. F. i Graham, S. (2006). «Primary-Grade Teachers' Use of Within-Class Ability Grouping in Reading». Journal of Educational Psychology, 98 (3), 529-541.

Comisión Europea (2006). Eficiencia y equidad en los sistemas europeos de educación y formación. Brussel·les, 8/9/2006, COM(2006) 481 final. SEC (2006) 1096.

De Haan, M. i Elbers, E. (2005). «Peer Tutoring in a Multiethnic Classroom in the Netherlands: A Multiperspective Analysis of Diversity». Comparative Education Review, 49 (3), 365-388.

Elboj, C., Puigdellívol, I., Soler, M. i Valls, R. (2002). Comunidades de aprendizaje. Transformar la educación. Barcelona: Graó.

Flecha, R., Soler, M. i Valls, R. (2008). «Lectura dialógica: interacciones que mejoran y aceleran la lectura». Revista Iberoamericana de Educación, (46), 71-87.

Flecha, R. (1997). Compartiendo palabras: el aprendizaje de las personas adultas a través del diálogo. Barcelona: Paidós.

Gatt, S., Ojala, M. i Soler, M. (2011). «Promoting Social Inclusion Counting with Everyone: Learning Communities and INCLUD-ED». International Studies in Sociology of Education, 21 (1), 33-47.

Gomez, J., Latorre, A., Sánchez, M. i Flecha, R. (2006). Metodología comunicativa crítica. Barcelona: El Roure.

Gómez, A., Puigvert, L. i Flecha, R. (2011). «Critical Communicative Methodology: Informing Real Social Transformation Through Research». Qualitative Inquiry, 17 (3), 235-245.

MIXSTRIN, Formas de agrupación del alumnado y su relación con el éxito escolar: 'mixture', 'streaming' e inclusión. Plan Nacional I+D+I. Ministerio de Educación y Ciencia (2009-2011). 
INCLUD-ED Project. Strategies for Inclusion and Social Cohesion in Europe from Education. 2006-2011. $6^{\text {th }}$ Framework Programme. Citizens and Governance in a Knowledge-based Society. Directorate-General for Research, European Commission.

INCLUD-ED (2011). Actuaciones de éxito en las escuelas europeas. Ministerio de Educación: Instituto de Formación del Profesorado, Investigación e Innovación Educativa (IFIIE).

Oliver, E., i Gatt, S. (2010). «De los actos comunicativos de poder a los actos comunicativos dialógicos en las aulas organizadas en grupos interactivos». Signos, 2010, 43 (2): 279-294.

Puigdellívol, I. i Krastina, L. (2010). «Inclusió i segregació a l'escola: pràctiques inclusives i excloents amb l'alumnat vulnerable». Temps d'Educació, (38), 95-113.

Youdell, D. (2003). «Identity Traps or How Black Students Fail: The Interactions between Biographical, Sub-cultural and Learner Identities». British Journal of Sociology of Education, 24 (1), 3-20.

Zimmer, R. (2003). «A New Twist in the Educational Tracking Debate». Economics of Education Revierw, 22 (3), 307. 
Xedagogia i Treball Social

Revista de Ciències Socials Aplicades

Edita: Universitat de Girona

Disseny i maquetació: info@clam.cat · 647427732

Dipòsit Legal: GI.904-2010

ISSN: 2013-9063 